\title{
Indirect decompression with lateral interbody fusion for severe degenerative lumbar spinal stenosis: minimum 1-year MRI follow-up
}

\author{
Takayoshi Shimizu, MD, PhD, Shunsuke Fujibayashi, MD, PhD, Bungo Otsuki, MD, PhD, \\ Koichi Murata, MD, PhD, and Shuichi Matsuda, MD, PhD \\ Department of Orthopaedic Surgery, Kyoto University Graduate School of Medicine, Kyoto, Japan
}

\begin{abstract}
OBJECTIVE The use of indirect decompression surgery for severe canal stenosis remains controversial. The purpose of this study was to investigate the efficacy of lateral interbody fusion (LIF) without posterior decompression in degenerative lumbar spinal spondylosis with severe stenosis on preoperative MRI.

METHODS This is a retrospective case series from a single academic institution. The authors included 42 patients ( 45 surgical levels) who were preoperatively diagnosed with severe degenerative lumbar stenosis on MRI based on the previously published Schizas classification. These patients underwent LIF with supplemental pedicle screw fixation without posterior decompression. Surgical levels were limited to $L 3-4$ and/or L4-5. All patients satisfied the minimum 1-year MRI follow-up. The authors compared the cross-sectional area (CSA) of the thecal sac and the clinical outcome scores (Japanese Orthopaedic Association [JOA] score) preoperatively, immediately postoperatively, and at the 1-year followup. Fusion status and disc height were evaluated based on CT scans obtained at the 1-year follow-up.
\end{abstract}

RESULTS The CSA improved over time, increasing from $54.5 \pm 19.2 \mathrm{~mm}^{2}$ preoperatively to $84.7 \pm 31.8 \mathrm{~mm}^{2}$ at 3 weeks postoperatively and to $132.6 \pm 37.5 \mathrm{~mm}^{2}$ at the last follow-up (average 28.3 months) $(p<0.001)$. The JOA score significantly improved over time (preoperatively $16.1 \pm 4.1,3$ months postoperatively $24.4 \pm 4.0$, and 1-year follow-up $25.7 \pm$ $2.9 ; p<0.001$ ). The fusion rate at the 1 -year follow-up was $88.8 \%$, and disc heights were significantly restored (preoperative, $6.3 \mathrm{~mm}$ and postoperative, $9.6 \mathrm{~mm} ; \mathrm{p}<0.001$ ). Patients showing poor CSA expansion ( $200 \%$ expansion rate) at the last follow-up had a higher prevalence of pseudarthrosis than patients with significant CSA expansion $>200 \%$ expansion rate) $(25.0 \%$ vs $3.4 \%, p<0.001)$. No major perioperative complications were observed.

CONCLUSIONS LIF with indirect decompression for degenerative lumbar disease with severe canal stenosis provided successful clinical outcomes, including restoration of disc height and indirect expansion of the thecal sac. Severe canal stenosis diagnosed on preoperative MRI itself is not a contraindication for indirect decompression surgery.

https://thejns.org/doi/abs/10.3171/2020.1.SPINE191412

KEYWORDS indirect decompression; lateral interbody fusion; severe; degenerative; lumbar spinal stenosis; MRI

$\mathrm{C}$ ONVENTIONAL surgical treatment for symptomatic degenerative lumbar spinal stenosis includes direct posterior decompression with or without fusion and posterior/transforaminal lumbar interbody fusion., ${ }^{7,8,19} \mathrm{In}$ 1997, Mayer first described a lateral retroperitoneal transpsoas approach to the anterior disc space. ${ }^{12}$ This approach, extreme lateral interbody fusion (LIF), was later modified and reported by Ozgur et al. ${ }^{16}$ More recently, Silvestre et al. and some authors introduced the oblique psoas-sparing approach, which is an approach through the corridor anterior to the psoas muscle, i.e., oblique lumbar interbody fu- sion. ${ }^{13,22,24}$ Regardless of the approach, studies have shown that LIF without posterior decompression can improve neurological symptoms through "indirect decompression" that results from the restoration of intervertebral and foraminal heights. ${ }^{3,15,18}$ However, the extent of the severity of canal stenosis, to which the indirect decompression is effective, remains unclear. If the indirect decompression is determined to be beneficial for degenerative lumbar diseases with severe canal stenosis, the criteria for LIF would further expand.

The purpose of this study was to assess the efficacy

ABBREVIATIONS CSA = cross-sectional area; $\mathrm{DH}-\mathrm{m}=$ disc height at the middle of the vertebral body; $\mathrm{DH}-\mathrm{p}=$ disc height at the posterior edge of the vertebral body; $\mathrm{EBL}$ = estimated blood loss; JOA = Japanese Orthopaedic Association; LIF = lateral interbody fusion; SDA = segmental disc angle.

SUBMITTED November 24, 2019. ACCEPTED January 13, 2020.

INCLUDE WHEN CITING Published online March 13, 2020; DOI: 10.3171/2020.1.SPINE191412. 


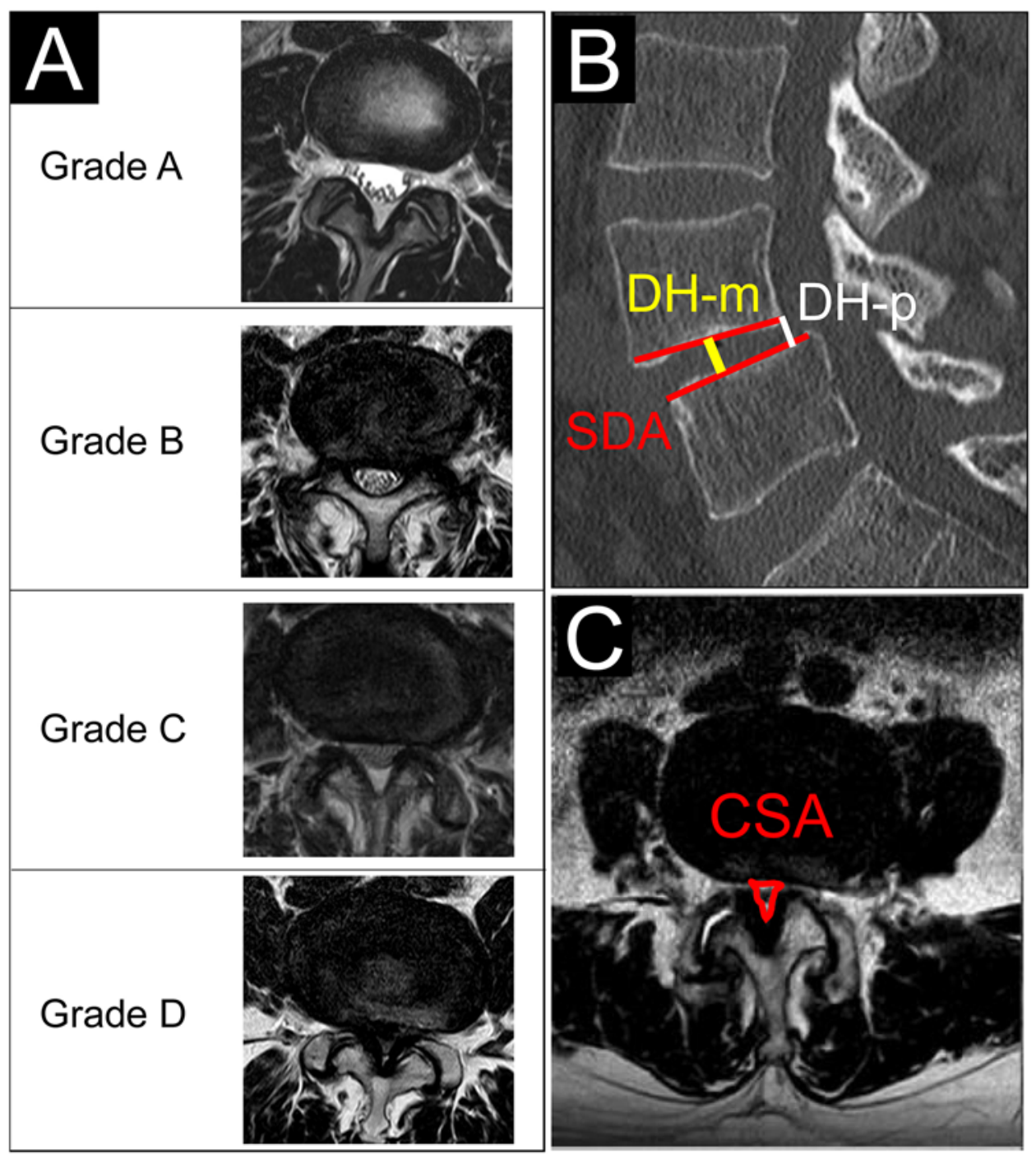

FIG. 1. A: Schizas classification for severity of lumbar spinal stenosis on MRI (grade A, CSF is clearly visible inside the dural sac; grade $\mathrm{B}$, rootlets occupy the entire dural sac but can still be individualized; grade $\mathrm{C}$, rootlets cannot be individualized with posterior epidural fat and invisible CSF; grade D, rootlets cannot be individualized without posterior epidural fat). B: Disc height (DH-m: middle, DH-p: posterior) and SDA measurement on CT imaging. C: CSA on MRI. Figure is available in color online only.

of LIF without posterior decompression for degenerative lumbar spinal disease with severe canal stenosis diagnosed on preoperative MRI. More specifically, we investigated the change in cross-sectional area (CSA) of the thecal sac over time on MRI during the minimum 1-year follow-up period.

\section{Methods}

\section{Patient Population and Data Collection}

After receiving institutional review board approval, we reviewed the medical records of the patients who underwent LIF surgery for degenerative lumbar conditions at a single academic institution between January 2012 and December 2018. A total of 257 patients were identified. Of the 257 patients, we included patients with age $>18$ years at time of surgery, L3-4 and/or L4-5 surgical level, severe canal stenosis on preoperative MRI evaluation (grades C and $\mathrm{D}$, determined according to the Schizas classification for severity of lumbar spinal stenosis based on the morphology of the dural sac; Fig. 1A), ${ }^{20}$ and available preoperative, 3 -week postoperative, and minimum 1-year followup MR images. Exclusion criteria were prior lumbar spine surgery (revision surgery), grade $>2$ spondylolisthesis, infectious diseases, and/or trauma. Sixty-eight patients had Schizas grade C or D at L3-4 and/or L4-5 surgical levels preoperatively. Of them, 26 patients were excluded for the following reasons: 14 for the lack of available follow-up MRI, 9 for an incomplete minimum 1-year follow-up, and 3 for prior lumbar surgery. Consequently, 42 patients with 45 surgical levels were included in the analysis.

Baseline demographics, including age, sex, BMI, tobacco use, and comorbidities, were investigated. Surgical data, including operative time, total estimated blood loss (EBL), cage height, and perioperative complications, were also collected. Clinical outcome was evaluated preopera- 
tively, at 3 weeks postoperatively, and at the 1-year followup using the Japanese Orthopaedic Association (JOA) score for degenerative lumbar diseases (overall score: 29), which includes subjective symptoms and objective clinical signs. ${ }^{6}$ The JOA score improvement rate (\%) was calculated according to the following formula: (postoperative JOA score - preoperative JOA score)/(29 - preoperative JOA score) $\times 100$.

\section{Surgical Procedure}

Surgery was performed based on the previously reported oblique lumbar interbody fusion procedure. ${ }^{4}$ Initially, we positioned the patient in a true lateral decubitus position under fluoroscopic guidance. We made a $4-$ to $5-\mathrm{cm}$ skin incision at the anterior axillary line, centered on the affected disc level, in the lateral abdominal region parallel to the fibers of the external oblique muscle and $5 \mathrm{~cm}$ frontally from the anterior border of the vertebral body. We preferred an approach from the left side. We accessed the retroperitoneal space by blunt dissection of the external oblique, internal oblique, and transverse abdominal muscles along the direction of their fibers. We exposed the intervertebral disc through an open corridor between the psoas muscle and aorta. We then placed a marker pin into the disc space from the anterolateral corner, which was identified fluoroscopically. Next, we placed sequential dilators to keep the operative field open. After making a portal by excising the annulus fibrosis, we removed the disc material, including the cartilaginous endplate and the annulus fibrosis, with a Cobb elevator under fluoroscopic guidance. An appropriate-sized cage (Clydesdale, Medtronic Inc.) was filled with synthetic bone substitute with or without autologous iliac crest bone graft depending on the surgeon's preference. We inserted the interbody cage in a press-fit fashion into the anterior third of the disc space to maximize the creation of segmental lordosis. No neuromonitoring was used during the surgery. After completion of the anterior procedure, the patient was turned prone, and we inserted supplemental posterior percutaneous pedicle screws. We locked the set screws on the rods in an in situ position without adding segmental compression.

\section{Radiographic Evaluation}

The presence of spondylolisthesis was determined if a plain lateral radiograph showed grade $\geq 1$ spondylolisthesis. CT scanning was routinely performed preoperatively and at the 1-year follow-up. Based on the CT scans, the disc height at the middle and posterior edge of the vertebral body (DH-m and DH-p, respectively; Fig. 1B) and the segmental disc angle (SDA; Fig. 1B) were measured; the Cobb angle between the inferior endplate of the upper vertebra and the superior endplate of the lower vertebra was also measured. The fusion rate was also evaluated on the CT scan at the 1-year follow-up. Solid fusion was determined if continuous trabecular bone inside the cage and/or bony union of the facet joint were observed without loosening of the screws.

\section{MRI Evaluation}

The severity of canal stenosis was evaluated based on the Schizas classification (grades A-D) preoperatively, at 3 weeks postoperatively, and at the 1-year follow-up. The CSA of the thecal sac was measured at the disc level with T2-weighted axial MRI (Fig. 1C) preoperatively, at 3 weeks postoperatively, and at the last follow-up (minimum 1 year postoperatively). ImageJ software (NIH) was used to measure the CSA in a hand-drawn fashion. The CSA expansion rate was calculated according to the following formula: (postoperative CSA/preoperative CSA) $\times 100$. The correlation between the postoperative CSA expansion rate and the JOA score improvement rate was also determined to assess the relationship of the radiographic and clinical outcomes. To investigate the risk factors for the poor CSA expansion at the last follow-up MRI, we subdivided the patients into two groups: the poor expansion group (postoperative CSA expansion rate $<200 \%$ ) and the good expansion group (postoperative CSA expansion rate $>200 \%$ ). The intergroup difference in the clinical parameters was analyzed to identify the risk factors for poor CSA expansion.

\section{Statistical Analysis}

Data are presented as mean \pm standard deviation, unless otherwise specified. The radiographic measurements were performed by a board-certified spine surgeon (T.S.), who was not involved in the surgeries. The interobserver reliability was assessed using intraclass correlation coefficients with data measured by one of the coauthors (B.O.) and classified as poor (0-0.39), moderate (0.4-0.74), or excellent (0.75-1). The JOA score, CSA, DH-m, DH-p, and SDA were compared among the preoperative and postoperative periods using the paired t-test or analysis of variance and Tukey's post hoc test according to the number of variables. Pearson's correlation test was used in the correlation analysis. The chi-square test and Mann-Whitney U-test were used for categorical and continuous variables, respectively, in the univariate analysis. Statistical significance was set at $\mathrm{p}<0.05$. JMP version 13 (SAS Institute) was used for all analyses.

\section{Results}

Table 1 shows the baseline demographics of the cohort included in the study. The mean age was $69.1 \pm 7.6$ years, and the BMI was $22.8 \pm 3.7 \mathrm{~kg} / \mathrm{m}^{2}$. One-level fusion was performed in $85.7 \%$ of patients (L3-4: $23.8 \%$ and L4-5: $61.9 \%$ ), and 2-level fusion was performed in $14.2 \%$. Spondylolisthesis was observed at $66.6 \%$ of the surgical levels. The mean operative time was $95.1 \pm 25.5$ minutes per level, including the intraoperative positioning change (from lateral decubitus to prone), and the mean total EBL was $17.7 \pm 21.2 \mathrm{ml}$ per level. The average cage height used was $10.6 \mathrm{~mm}$. Overall, the interrater reliability for the radiographic measurements was excellent (intraclass correlation coefficients: 0.984 for CSA, 0.937 for DH-m, 0.945 for DH-p, and 0.948 for SDA).

\section{Clinical Outcome}

The JOA score significantly improved over time (preoperatively $16.1 \pm 4.1,3$ months postoperatively $24.4 \pm 4.0$, and 1-year follow-up $25.7 \pm 2.9 ; \mathrm{p}<0.001$ ) (Fig. 2A). The 
average JOA score improvement rates were $66.8 \%$ and $74.9 \%$ at the 3-month and 1-year follow-ups, respectively. The disc heights were significantly restored postoperatively (DH-m: $6.3 \pm 2.4 \mathrm{~mm}$ preoperatively vs $9.6 \pm 1.8 \mathrm{~mm}$ at the 1-year follow-up, p < 0.001; and DH-p: $3.7 \pm 1.6 \mathrm{~mm}$ preoperatively vs $5.7 \pm 1.7 \mathrm{~mm}$ at the 1-year follow-up, $\mathrm{p}$ $<0.001$ ) (Fig. 2B). The SDA was also restored $\left(4.6^{\circ} \pm 4.0^{\circ}\right.$ preoperatively vs $6.4^{\circ} \pm 3.1^{\circ}$ at the 1 -year follow-up; $\mathrm{p}<$ $0.001)$. The fusion rate at the 1-year follow-up was $88.8 \%$ (Table 2). Perioperative complications included incidental anterior longitudinal ligament rupture $(\mathrm{n}=1)$, approachassociated transient thigh pain/numbness $(\mathrm{n}=2)$, and retroperitoneal hematoma $(n=2)$. No major vascular, ureter, or colon injury occurred. No patients underwent revision surgery during the follow-up period.

\section{MRI Evaluation}

The preoperative Schizas classifications were grades $\mathrm{C}$ and $\mathrm{D}$ in 30 and 15 patients, respectively. The average MRI follow-up was $29.6 \pm 15.7$ months postoperatively (minimum 1-year follow-up). This significantly improved postoperatively ( 3 weeks postoperatively: grades $\mathrm{A}, \mathrm{n}=$ $14 ; \mathrm{B}, \mathrm{n}=14 ; \mathrm{C}, \mathrm{n}=14$; and $\mathrm{D}, \mathrm{n}=3$; and at last follow-up: $\mathrm{A}, \mathrm{n}=37 ; \mathrm{B}, \mathrm{n}=4$; and $\mathrm{C}, \mathrm{n}=3$ ). The CSA also improved over time, increasing from $54.5 \pm 19.2 \mathrm{~mm}^{2}$ preoperatively to $84.7 \pm 31.8 \mathrm{~mm}^{2}$ at 3 weeks postoperatively and to 132.6 $\pm 37.5 \mathrm{~mm}^{2}$ at the last follow-up ( $<0.001$ ) (Fig. 2C). The average CSA expansion rates were $172.0 \%$ and $274.0 \%$ at the 3 -week and 1-year follow-ups, respectively. Figure 3 is the scatterplot showing that no significant correlation was observed between the CSA expansion rate and the JOA score improvement rate at 3 months postoperatively $(\mathrm{r}=$ $0.225, \mathrm{p}=0.133)$.

\section{Risk Factors for Poor CSA Expansion}

Twenty-nine surgical levels showed a good CSA expansion rate $(>200 \%)$, whereas 16 levels showed a poor CSA expansion rate $(<200 \%)$. Of the demographic and radiographic parameters that could clinically contribute to the poor CSA expansion rate, the univariate analysis revealed intergroup difference in preoperative CSA (67.0 $\pm 17.8 \mathrm{~mm}^{2}$ vs $\left.47.6 \pm 16.5 \mathrm{~mm}^{2}\right)$ and absence of solid fusion (pseudarthrosis) at the 1-year follow-up CT (25.0\% vs $3.4 \%$ ) (Table 3).

\section{Discussion}

In this clinical case series, we showed successful 1-year clinical outcome of LIF without posterior decompression in degenerative lumbar spinal disease with severe canal stenosis diagnosed on preoperative MRI. The CSA of the thecal sac on MRI expanded postoperatively over time during the minimum 1-year follow-up period.

Several authors have reported on the clinical outcomes of indirect decompression surgery for degenerative lumbar disease. Kepler et al. found that the Oswestry Disability Index scores improved from an average of $32.8 \pm 9.8$ preoperatively to $19.8 \pm 9.8$ postoperatively at the 6 -month follow-up. ${ }^{9}$ A recent report by Pereira et al. demonstrated that the clinical outcomes at the 1-year follow-up showed $39 \%, 50 \%$, and 60\% improvements in the Oswestry Dis-
TABLE 1. Patient demographics

\begin{tabular}{lc}
\hline & Value \\
\hline No. of patients & 42 \\
\hline No. of levels & 45 \\
\hline Mean age, yrs (range) & $69.1 \pm 7.6(53-85)$ \\
\hline Sex, M/F & $13: 29$ \\
\hline Mean BMl, kg/m ${ }^{2}$ & $22.8 \pm 3.7$ \\
\hline Tobacco user, $\mathrm{n}(\%)$ & $8(19.0)$ \\
\hline Comorbidity, $\mathrm{n}$ & \\
Diabetes mellitus & 9 \\
Collagen diseases & 4 \\
Rheumatoid arthritis & 2 \\
\hline Malignancy & 3 \\
\hline Kidney transplantation & 1 \\
\hline Spondylolisthesis at surgical level, $\mathrm{n}(\%)$ & $30(66.6)$ \\
\hline Surgical level, $\mathrm{n}$ (\%) & $10(23.8)$ \\
\hline L3-4 & $26(61.9)$ \\
\hline L4-5 & $6(14.3)$ \\
\hline L3-4 \& L4-5 (2-level) & $95.1 \pm 25.5$ \\
\hline Mean op time per 1 level, mins & $17.7 \pm 21.2$ \\
\hline Mean total EBL per 1 level, $\mathrm{ml}$ & $10.6(8-14)$ \\
\hline Mean cage height, mm (range)
\end{tabular}

Continuous data are shown as mean $\pm \mathrm{SD}$.

ability Index, back visual analog scale, and leg visual analog scale scores, respectively. ${ }^{18}$ However, none of these studies have focused on cases with severe canal stenosis. The inclusion criteria for the present study were strictly in regard to the severity of canal stenosis; only the preoperative Schizas classification grades C and D, representing complete MR myelographic canal block, were included. Furthermore, we focused on the L3-4 and L4-5 surgical levels, which are the typical lumbar spinal levels where degenerative changes occur. We believe that these specific criteria have ensured strong clinical evidence on the current data. In addition to the successful clinical score (JOA score improvement of $74.9 \%$ at the 1-year follow-up), the excellent fusion rate at 1 year $(88.8 \%)$ was found to align with previous reports describing fusion rates of $88.0 \%$ $97.2 \%$ for LIF in degenerative lumbar disease. , $^{10,17,23}$

In our series, the average disc height at the 1-year follow-up $(9.6 \mathrm{~mm})$ was nearly the same height as the average cage height inserted $(10.6 \mathrm{~mm})$, indicating that only subtle cage subsidence occurred. This could be due to the rigidity of the supplemental pedicle screw fixation. Prior studies have shown that a stand-alone cage may result in a $22.4 \%-31.3 \%$ subsidence rate. ${ }^{1,11,21,23}$ We believe that supplemental pedicle screw replacement is extremely helpful in preventing cage subsidence.

In a recent meta-analysis comparing the complication rates of trans- and pre-psoas approaches, the trans-psoas group had a higher rate of approach-side sensory symptoms $(21.7 \%$ vs $8.7 \%)$ and hip flexor weakness $(19.7 \%$ vs $5.7 \%$ ), whereas the pre-psoas group had significantly higher major vascular injury (1.8\% vs $0.4 \%){ }^{23}$ Although the approach-associated complication has been shown to 


\section{A JOA Score Change}

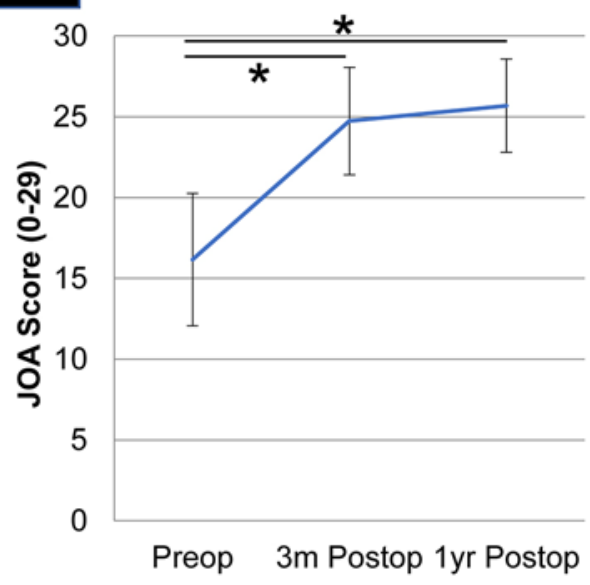

C CSA Change on MRI

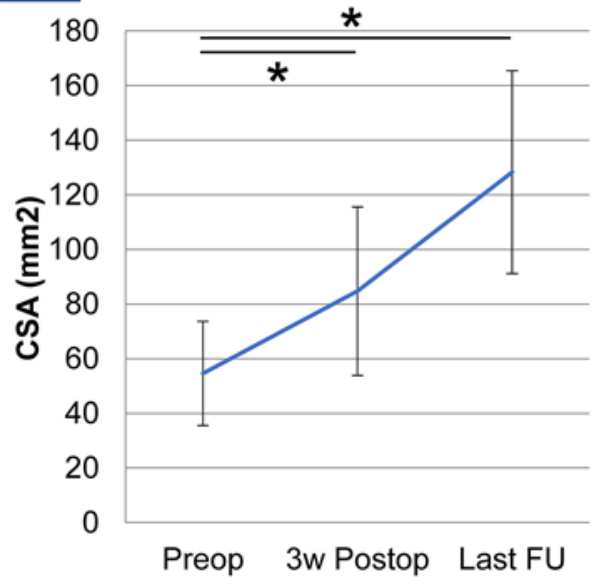

\section{B Disc Height/Angle Change on CT}

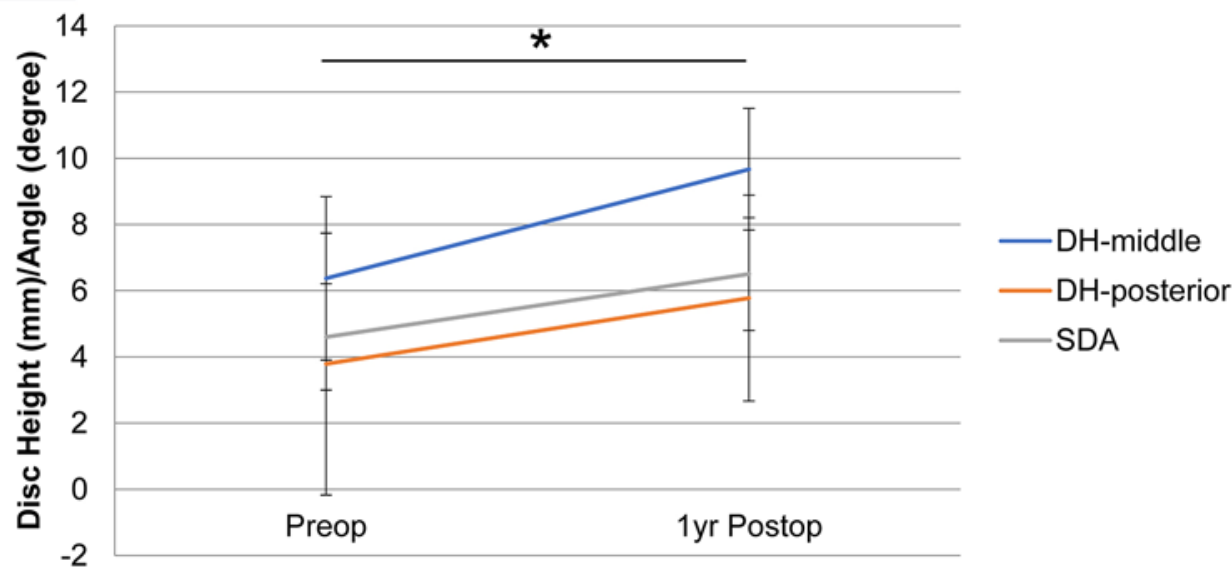

FIG. 2. A: Change in JOA score at 3 months and 1 year postoperatively. B: Change in DH-m, DH-p, and SDA on the 1-year followup CT scan. C: Change in CSA on MRI at the 3-week and last follow-ups (average 28 months). ${ }^{*} p<0.001$. Figure is available in color online only.

be transient, ${ }^{5}$ a pre-psoas approach with direct visualization of the operative field makes the complication rate less frequent. Recently, we prefer to split the psoas at the anterior third of the muscle belly after blunt dissection of the fascia. This prevents major vascular injury as well as sympathetic nerve injury.

Our MRI analysis showed that substantial CSA expansion can occur following indirect decompression even in patients with severe canal stenosis. An average of $172.0 \%$

\section{TABLE 2. Fusion rate and perioperative complications}

\begin{tabular}{lc}
\hline & Value (\%) \\
\hline Fusion rate at 1-yr follow-up & $40 / 45(88.8)$ \\
\hline Periop complication & $1 / 42(2.4)$ \\
\hline ALL rupture & $2 / 42(4.8)$ \\
\hline Approach-associated thigh pain/numbness & $2 / 42(4.8)$ \\
\hline
\end{tabular}

$\mathrm{ALL}=$ anterior longitudinal ligament.

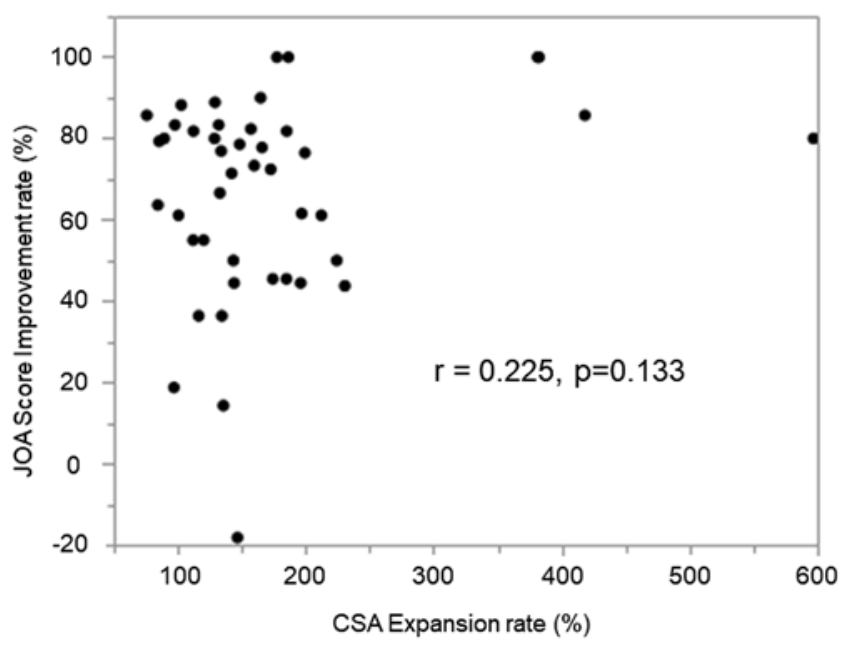

FIG. 3. Scatterplot of JOA score improvement and CSA expansion rate, showing no significant correlation $(r=0.225, p=0.133)$. 
TABLE 3. Univariate risk factor analysis for poor CSA expansion rate $(<200 \%)$ at the last follow-up

\begin{tabular}{lccc}
\hline & $\begin{array}{c}\text { Poor Group } \\
(\mathrm{n}=16)\end{array}$ & $\begin{array}{c}\text { Good Group } \\
(\mathrm{n}=29)\end{array}$ & $\begin{array}{c}\mathrm{p} \\
\text { Value }\end{array}$ \\
\hline Mean age, yrs & $69.7 \pm 7.3$ & $69.0 \pm 8.0$ & 0.759 \\
\hline Female sex, $\mathrm{n}(\%)$ & $10(62.5)$ & $21(72.4)$ & 0.491 \\
\hline Mean BMI, $\mathrm{kg} / \mathrm{m}^{2}$ & $23.2 \pm 5.6$ & $22.7 \pm 3.1$ & 0.715 \\
\hline Spondylolisthesis, $\mathrm{n}(\%)$ & $10(62.5)$ & $20(69.0)$ & 0.660 \\
\hline Mean preop CSA, $\mathrm{mm}^{2}$ & $67.0 \pm 17.8$ & $47.6 \pm 16.5$ & $<0.001$ \\
\hline Mean preop DH-m, mm & $5.6 \pm 2.4$ & $6.7 \pm 2.4$ & 0.129 \\
\hline Mean preop DH-p, mm & $3.5 \pm 1.4$ & $3.8 \pm 1.7$ & 0.560 \\
\hline Mean preop SDA, ${ }^{\circ}$ & $3.8 \pm 3.4$ & $5.0 \pm 4.2$ & 0.329 \\
\hline Mean postop DH-m, mm & $9.0 \pm 1.6$ & $9.9 \pm 1.8$ & 0.100 \\
\hline Mean postop DH-p, mm & $5.3 \pm 1.5$ & $6.0 \pm 1.8$ & 0.243 \\
\hline Mean postop SDA, ${ }^{\circ}$ & $6.0 \pm 3.1$ & $6.7 \pm 3.1$ & 0.489 \\
\hline Pseudarthrosis, $\mathrm{n}(\%)$ & $4(25.0)$ & $1(3.4)$ & 0.027 \\
\hline
\end{tabular}

expansion was seen at the immediate postoperative period (3 weeks postoperatively) and continued to expand to $274.0 \%$ during the average 29.6-month follow-up. A typical MRI evaluation showed the immediate CSA expansion due to disc height restoration and improvement of ligamentum flavum buckling, then gradual shrinking of disc bulging and ligamentum flavum along with the progression of bony fusion (Fig. 4). This spontaneous longterm shrinkage of the ligamentum flavum after anterior interbody fusion has been previously reported..$^{14}$ However, the CSA expansion rate had no significant correlation with the clinical score (JOA score). This indicates that clinical score improvement is instead associated with the effect of stabilization rather than that of the neural decompression. From this perspective, supplemental screw fixation would be recommended. Nevertheless, we believe that radiographic improvement still has a significant importance in postoperative discussions with patients. In addition, at long-term follow-up, which we could not address in this study, CSA expansion may be significantly relevant to clinical outcome, especially in patients with pseudarthrosis (in case of loss of rigid stabilization). Therefore, we evaluated the risk factors for the degree of CSA expansion.

There has been no previously published evidence regarding the threshold of the CSA expansion ratio that is correlated with clinical outcome. According to our average data (172.0\% expansion ratio) and for the ease of use, we defined the threshold as $>200 \%$, and all of the patients with $>200 \%$ expansion had Schizas grade A or B, which indicates negative canal stenosis. Pseudarthrosis was more frequently observed in the patients with poor CSA expan-
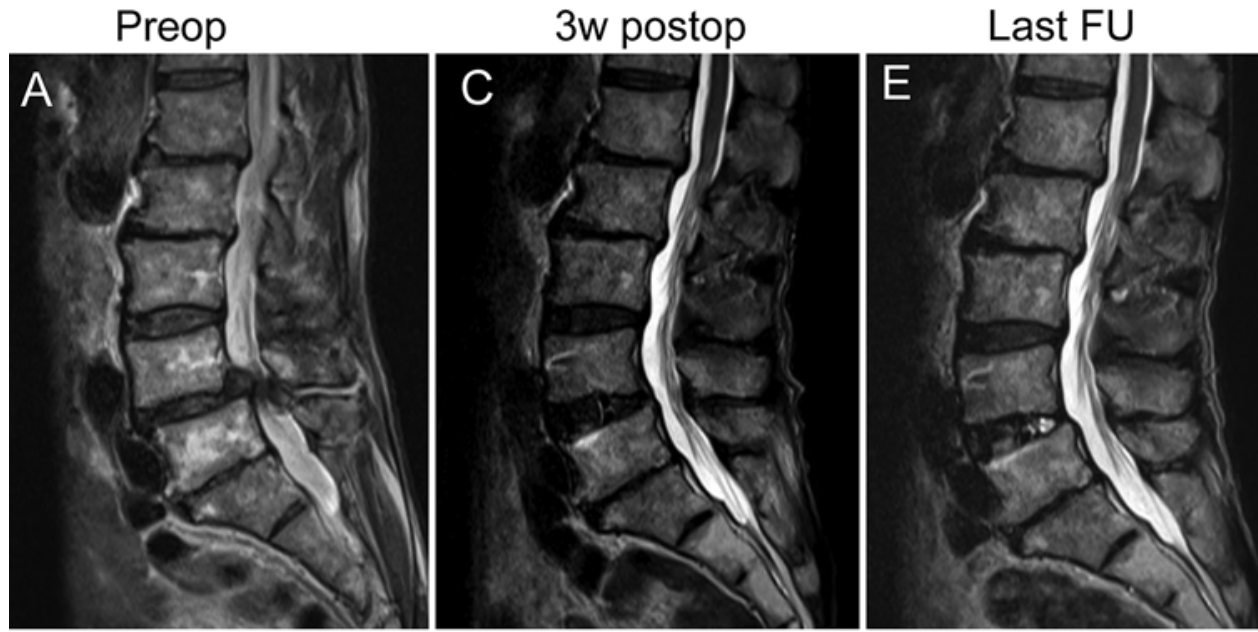

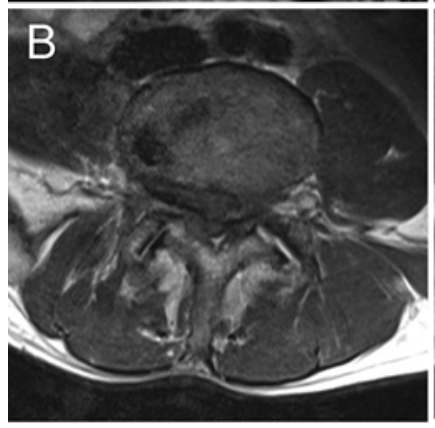

CSA $25.3 \mathrm{~mm}^{2}$

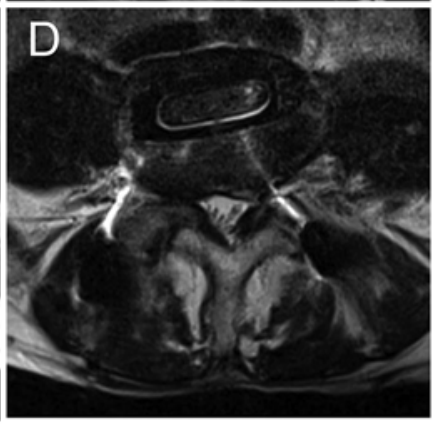

CSA $105.8 \mathrm{~mm}^{2}$ $420 \%$ expansion

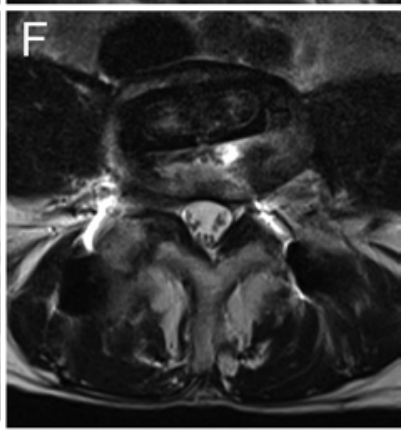

CSA $146.4 \mathrm{~mm}^{2}$ $580 \%$ expansion

FIG. 4. A and B: Typical case of preoperative severe canal stenosis (CSA, $\left.25.3 \mathrm{~mm}^{2}\right)$. C and D: Three weeks postoperatively, significant expansion is seen due to disc height restoration and improvement of ligamentum flavum buckling. $E$ and $F$ : At the last follow-up (14 months), further CSA expansion is observed with shrinking of the disc bulging and ligamentum flavum. FU = follow-up. 

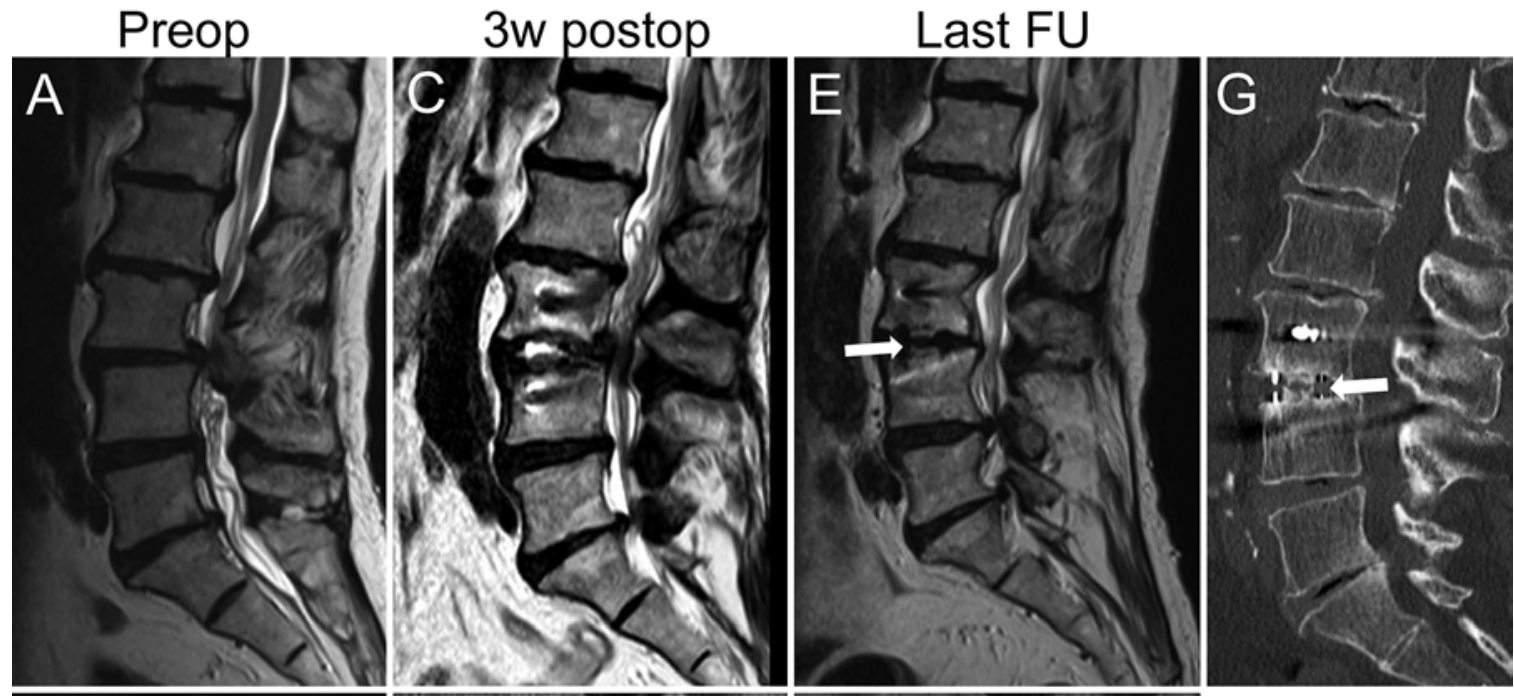

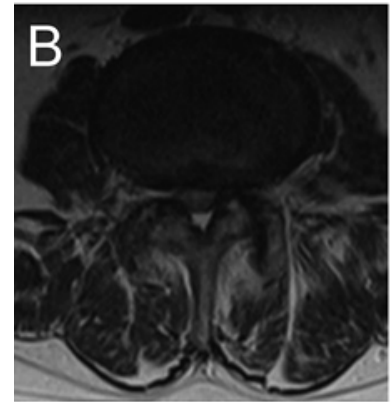

CSA $48.1 \mathrm{~mm}^{2}$

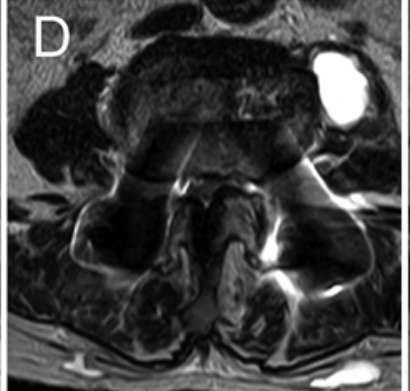

CSA $46.4 \mathrm{~mm}^{2}$

$96 \%$ expansion

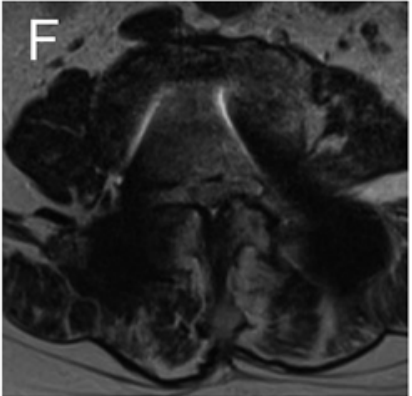

CSA $70.7 \mathrm{~mm}^{2}$

$141 \%$ expansion

FIG. 5. A and B: A case of preoperative severe canal stenosis (CSA, $\left.48.1 \mathrm{~mm}^{2}\right)$. C and D: Three weeks postoperatively, poor expansion (96\% expansion rate) is seen. $\mathbf{E}$ and $\mathbf{F}$ : At the last follow-up (29 months), CSA expansion is still subtle, with clear pseudarthrosis inside the cage (white arrow). G: CT image at the 1-year follow-up, also showing pseudarthrosis (white arrow).

sion than in those with good expansion (25.0\% vs 3.4\%) (Fig. 5). Solid fusion is necessary for promoting and maintaining CSA expansion during the long-term follow-up. Our data showed that a large preoperative CSA was the risk factor for poor expansion at last follow-up. In other words, a small preoperative CSA tended to have greater expansion, which implies that small preoperative CSA is not necessarily a contraindication for indirect decompression.

Some limitations should be noted. This study is a small retrospective case series. Furthermore, there was no control group. A prospective study with a control group undergoing conventional posterior/transforaminal interbody fusion with direct decompression is needed to determine actual clinical relevance. In addition, there was substantial selection bias because the patients with extraligamentous disc herniation, locked facet, and stenosis due to bony structure (osteophyte of the facet/vertebra) were originally excluded. These conditions should be carefully reviewed preoperatively. In this series, the patients without spondylolisthesis (33.4\%) underwent fusion surgery for the following reasons: intractable back pain with evidence of radiographic disc degeneration, significant intervertebral instability on dynamic flexion-extension radiographs, and/or foraminal stenosis on MRI parasagittal views. Although we believe that decompression alone might not have worked for these patients, this relatively aggressive criterion for fusion possibly caused selection bias. This study did not include the L5-S1 level, where degenerative change is usually seen. We are gathering data on L5-S1 indirect decompression, which will be included in future research.

\section{Conclusions}

LIF with indirect decompression for degenerative lumbar disease with severe canal stenosis provided successful clinical outcomes throughout the 1-year postoperative period, including restoration of disc height and indirect expansion of the thecal sac. LIF is an effective surgical option and can be indicated for severe lumbar canal stenosis. Achieving solid fusion may be necessary to maintain the expansion of the dural sac throughout the postoperative period.

\section{References}

1. Ahmadian A, Bach K, Bolinger B, et al. Stand-alone mini- 
mally invasive lateral lumbar interbody fusion: multicenter clinical outcomes. J Clin Neurosci. 2015;22(4):740-746.

2. Alimi M, Hofstetter CP, Cong GT, et al. Radiological and clinical outcomes following extreme lateral interbody fusion. J Neurosurg Spine. 2014;20(6):623-635.

3. Aichmair A, Lykissas MG, Girardi FP, et al. An institutional six-year trend analysis of the neurological outcome after lateral lumbar interbody fusion: a 6-year trend analysis of a single institution. Spine (Phila Pa 1976). 2013;38(23):E1483E1490.

4. Fujibayashi S, Hynes RA, Otsuki B, et al. Effect of indirect neural decompression through oblique lateral interbody fusion for degenerative lumbar disease. Spine (Phila Pa 1976). 2015;40(3):E175-E182.

5. Fujibayashi S, Kawakami N, Asazuma T, et al. Complications associated with lateral interbody fusion: nationwide survey of 2998 cases during the first 2 years of its use in Japan. Spine (Phila Pa 1976). 2017;42(19):1478-1484.

6. Fujiwara A, Kobayashi N, Saiki K, et al. Association of the Japanese Orthopaedic Association score with the Oswestry Disability Index, Roland-Morris Disability Questionnaire, and Short-Form 36. Spine (Phila Pa 1976). 2003;28(14):16011607.

7. Ghogawala Z, Dziura J, Butler WE, et al. Laminectomy plus fusion versus laminectomy alone for lumbar spondylolisthesis. N Engl J Med. 2016;374(15):1424-1434.

8. Glassman S, Gornet MF, Branch C, et al. MOS Short Form 36 and Oswestry Disability Index outcomes in lumbar fusion: a multicenter experience. Spine J. 2006;6(1):21-26.

9. Kepler CK, Sharma AK, Huang RC, et al. Indirect foraminal decompression after lateral transpsoas interbody fusion. $J$ Neurosurg Spine. 2012;16(4):329-333.

10. Kotwal S, Kawaguchi S, Lebl D, et al. Minimally invasive lateral lumbar interbody fusion: clinical and radiographic outcome at a minimum 2-year follow-up. J Spinal Disord Tech. 2015;28(4):119-125.

11. Marchi L, Abdala N, Oliveira L, et al. Radiographic and clinical evaluation of cage subsidence after stand-alone lateral interbody fusion. J Neurosurg Spine. 2013;19(1):110-118.

12. Mayer HM. A new microsurgical technique for minimally invasive anterior lumbar interbody fusion. Spine (Phila Pa 1976). 1997;22(6):691-700.

13. Mehren C, Mayer HM, Zandanell C, et al. The oblique anterolateral approach to the lumbar spine provides access to the lumbar spine with few early complications. Clin Orthop Relat Res. 2016;474(9):2020-2027.

14. Ohtori S, Orita S, Yamauchi K, et al. Change of lumbar ligamentum flavum after indirect decompression using anterior lumbar interbody fusion. Asian Spine J. 2017;11(1):105-112.

15. Oliveira L, Marchi L, Coutinho E, Pimenta L. A radiographic assessment of the ability of the extreme lateral interbody fusion procedure to indirectly decompress the neural elements. Spine (Phila Pa 1976). 2010;35(26)(suppl):S331-S337.

16. Ozgur BM, Aryan HE, Pimenta L, Taylor WR. Extreme Lateral Interbody Fusion (XLIF): a novel surgical technique for anterior lumbar interbody fusion. Spine J. 2006;6(4):435-443.

17. Patel NP, Birch BD, Dement SE, Elbert GA. The mini-open anterolateral approach for degenerative thoracolumbar disease. Clin Neurol Neurosurg. 2010;112(10):853-857.
18. Pereira EA, Farwana M, Lam KS. Extreme lateral interbody fusion relieves symptoms of spinal stenosis and low-grade spondylolisthesis by indirect decompression in complex patients. J Clin Neurosci. 2017;35:56-61.

19. Rouben D, Casnellie M, Ferguson M. Long-term durability of minimal invasive posterior transforaminal lumbar interbody fusion: a clinical and radiographic follow-up. J Spinal Disord Tech. 2011;24(5):288-296.

20. Schizas C, Theumann N, Burn A, et al. Qualitative grading of severity of lumbar spinal stenosis based on the morphology of the dural sac on magnetic resonance images. Spine (Phila Pa 1976). 2010;35(21):1919-1924.

21. Sharma AK, Kepler CK, Girardi FP, et al. Lateral lumbar interbody fusion: clinical and radiographic outcomes at 1 year: a preliminary report. J Spinal Disord Tech. 2011;24(4):242250.

22. Silvestre C, Mac-Thiong JM, Hilmi R, Roussouly P. Complications and morbidities of mini-open anterior retroperitoneal lumbar interbody fusion: oblique lumbar interbody fusion in 179 patients. Asian Spine J. 2012;6(2):89-97.

23. Walker CT, Farber SH, Cole TS, et al. Complications for minimally invasive lateral interbody arthrodesis: a systematic review and meta-analysis comparing prepsoas and transpsoas approaches. J Neurosurg Spine. 2019;30(4):446-460.

24. Woods KR, Billys JB, Hynes RA. Technical description of oblique lateral interbody fusion at L1-L5 (OLIF25) and at L5-S1 (OLIF51) and evaluation of complication and fusion rates. Spine J. 2017;17(4):545-553.

\section{Disclosures}

The authors report no conflict of interest concerning the materials or methods used in this study or the findings specified in this paper.

\section{Author Contributions}

Conception and design: Shimizu. Acquisition of data: Shimizu, Murata. Analysis and interpretation of data: Shimizu, Otsuki, Murata. Drafting the article: Shimizu. Critically revising the article: Fujibayashi, Otsuki, Murata. Reviewed submitted version of manuscript: Fujibayashi, Otsuki, Matsuda. Statistical analysis: Otsuki. Study supervision: Fujibayashi, Matsuda.

\section{Supplemental Information}

\section{Previous Presentations}

A portion of the abstract of this study was presented at the following academic congresses: quick fire presentation at EUROSPINE 2019, Helsinki, Finland, October 16-18, 2019; and poster presentation at the 26th International Meeting on Advanced Spine Techniques (IMAST), Amsterdam, the Netherlands, July 17-20, 2019.

\section{Correspondence}

Takayoshi Shimizu: Kyoto University Graduate School of Medicine, Kyoto, Japan. takayosh@kuhp.kyoto-u.ac.jp. 